\title{
Plasmid-mediated Transfer of Host-range Specificity Between Two Strains of Rhizobium leguminosarum
}

\author{
By N. J. BREWIN, * J. E. BERINGER† AND A. W. B. JOHNSTON \\ John Innes Institute, Colney Lane, Norwich NR4 $7 U H$
}

(Received 11 April 1980)

\begin{abstract}
Transfer of nodulation ability $\left(\mathrm{Nod}^{+}\right)$from derivatives of Rhizobium leguminosarum strain TOM to strain 16015 , a non-nodulating mutant of strain 300 , occurred at frequencies of $10^{-5}$ to $10^{-6}$ per recipient. All $39 \mathrm{Nod}^{+}$derivatives of strain 16015 examined had the host-range specificity of the donor strain TOM, i.e. the ability to nodulate the pea cultivar 'Afghanistan' and the primitive pea line JI 241 in addition to the commercial variety 'Wisconsin Perfection' which can be nodulated by strain 300 . The transfer of $\mathrm{Nod}^{+}$was associated with the appearance in strain 16015 of a new plasmid band on agarose gels (mol. wt about $160 \times 10^{6}$ ) which corresponded in size to one of the three plasmid bands found in strain TOM: we term this new plasmid pRL5JI. In addition to genes for Nod ${ }^{+}$ and host-range, the plasmid pRL5JI carries genes for nodule function $\left(\mathrm{Fix}^{+}\right)$that are absent from strain 16015. Although strain TOM produces a medium-sized bacteriocin, this property was not co-transferred with pRL5JI. The introduction of pRL5JI did not result in the elimination of any of the resident plasmids of strain 16015. The plasmid pRL5JI differs in many respects from the transmissible bacteriocinogenic plasmids pRL1JI, pRL3JI and pRL4JI previously found, and it appears to belong to a different incompatibility group.
\end{abstract}

\section{INTRODUCTION}

Large plasmids, of molecular weight $>100 \times 10^{6}$, are abundant in Rhizobium strains (Casse et al., 1979; Gross et al., 1979; Hirsch et al., 1980) and apparently play an important role in determining the interaction of the bacterium with the host plant (Johnston et al., 1978; Casse et al., 1979; Nuti et al., 1979), as they also do in other members of the Rhizobiaceae such as Agrobacterium tumefaciens (see review by van Montagu \& Schell, 1979) and Agrobacterium rhizogenes (Moore et al., 1979). In the case of $A$.tumefaciens the tumourinducing plasmid has been shown to determine host-range specificity (Loper \& Kado, 1979; Thomashow et al., 1980); the plasmid-mediated transfer of nodulation ability for peas from a strain of $R$. leguminosarum to strains of $R$. trifolii and $R$. phaseoli (Johnston et al., 1978 ) should perhaps be regarded as the same kind of phenomenon.

Strains of $R$. leguminosarum form nodules on members of the Viciaceae, namely Pisum, Lens, Lathyrus and Vicia spp. However, even within this single cross-inoculation group of bacteria, certain restrictions on host-range are known. For example, the pea cultivar 'Afghanistan' is not nodulated by most strains of $R$. leguminosarum isolated in western Europe, and this resistance to nodulation has been ascribed to an allele, sym-2, in the genome of cv. Afghanistan (Holl, 1975). However, a strain of $R$. leguminosarum (TOM) isolated in Turkey is able to nodulate cv. Afghanistan as well as most of the commercial pea varieties such as 'Alaska' and 'Wisconsin Perfection' (Winarno \& Lie, 1979).

$\dagger$ Present address: Rothamsted Experimental Station, Harpenden, Herts AL5 2JQ. 
Table 1. Pea lines, bacterial strains and plasmids

Pea lines

cv. Afghanistan

JI 241
Wisconsin Perfection
Characteristics

sym-2

Similar to cv. Afghanistan
Source/reference

Commercial variety

Lie et al. (1976)

Genetic stock John Innes Institute

Johnston \& Beringer (1975)

Field isolate; $\mathrm{Nod}^{+}$on Wisconsin Perfection; Nod- on cv. Afghanistan and $\mathrm{Jl} 241^{*}$

3841

16015

6007

T3

TOM

3706

248

239

336

Plasmids $\dagger$

pRL1JI

pRL3JI

pRL4JI

pRL5JI

pJB5JI

pVW3JI

pVW5JI

R68.45

pJB3JI
300 str -277

300 str-37 spc-54 nod -6007

300 phe-1 trp-12 str-37 nod-6007

300 ura-14 trp-16 str-86 (pJB5JI)

Field isolate; Nod $^{+}$on Wisconsin

Perfection; $\mathrm{Nod}^{+}$on cv. Afghanistan and JI 241

TOM rif-305

Field isolate

Field isolate

Field isolate

\author{
Med ${ }^{+} \mathrm{Tra}^{+} \mathrm{Nod}^{+} \mathrm{Fix}^{+}$ \\ $\mathrm{Med}^{+} \mathrm{Tra}^{+}$ \\ Med + Tra ${ }^{+}$ \\ $\mathrm{Tra}^{+} \mathrm{Nod}^{+} \mathrm{Fix}^{+}$ \\ pRL1JI::Tn5 \\ pRL3JI::Tn5 \\ pRL4JI::Tn5 \\ P1-group R-plasmid from \\ Pseudomonas aeruginosa
}

$\mathrm{R} 68.45 \mathrm{Km}^{*}$
This study

Brewin et al. (1980)

Johnston \& Beringer (1976)

Johnston et al. (1978)

Winarno \& Lie (1979)

This study

Hirsch (1979)

Hirsch (1979)

Hirsch (1979)

Hirsch (1979)

Hirsch (1979)

Hirsch (1979)

This study

Johnston et al. (1978)

Brewin et al. (1980)

Brewin et al. (1980)

Haas \& Holloway (1976)

This laboratory

* Occasional nodules are formed by strain 300 derivatives on cv. Afghanistan and JI 241. For this reason a strain of $R$. leguminosarum was defined as non-nodulating $\left(\mathrm{Nod}^{-}\right)$on that particular legume host if it always formed less than five nodules per plant.

$\dagger \mathrm{Med}^{+}$means that the plasmid specifies medium bacteriocin production; $\mathrm{Tra}^{+}$means transmissible by conjugation; $\mathrm{Nod}^{+}$and $\mathrm{Fix}^{+}$refer to nodulation and fixation functions that are absent from $R$. leguminosarum strain 16015.

We here report that the particular host-range characteristics of TOM represent a plasmidborne trait that can be transferred at low frequency to a strain of $R$. leguminosarum which does not normally nodulate cv. Afghanistan or another primitive pea line, JI 241, which has similar infection specificity to cv. Afghanistan.

\section{METHODS}

Pea varieties, bacterial strains and plasmids. These are described in Table 1.

Genetic manipulations. Bacteria were grown on minimal (Y) or rich (TY) medium (Beringer, 1974) supplemented as required with rifampicin $\left(20 \mu \mathrm{g} \mathrm{m}^{-1}\right)$, streptomycin $\left(200\right.$ or $\left.500 \mu \mathrm{g} \mathrm{ml}^{-1}\right)$, spectinomycin $(200$ $\left.\mu \mathrm{g} \mathrm{ml}^{-1}\right)$ and kanamycin $\left(20 \mu \mathrm{g} \mathrm{ml}^{-1}\right)$. Membrane crosses were made as described by Beringer et al. (1978). For routine nodulation tests, peas were grown on $1 \%(w / v)$ agar containing Fahraeus medium (Vincent, 1970) in a glasshouse at $20^{\circ} \mathrm{C}$. Conversion of acetylene to ethylene was used as an assay of nitrogenase activity (Johnston \& Beringer, 1975).

Bacteriocin production. Production of bacteriocins was determined by the method of Hirsch (1979). Rhizobium leguminosarum strain 248 was used as an indicator for small bacteriocins and either strain 239 or strain $\mathbf{3 3 6}$ as indicator for medium bacteriocins.

Selection for transfer of nodulation ability. Direct selection for the transfer of nodulation ability followed the method of Brewin et al. (1980) which exploits the fact that both for JI 241 (N. J. Brewin, unpublished observations) and for Wisconsin Perfection an inoculum containing as few as 10 nodulating cells among $10^{7}$ non-nodulating derivatives is sufficient to allow nodules to develop from which nodulating clones can be 
recovered after surface sterilization for $30 \mathrm{~s}$ in $10 \%(\mathrm{w} / \mathrm{v})$ sodium hypochlorite. After a membrane cross, the donor strain (which was sensitive to streptomycin) was counter-selected by incubating approximately $2 \times 10^{7}$ cells on plates containing streptomycin $\left(500 \mu \mathrm{g} \mathrm{ml}^{-1}\right)$ for $2 \mathrm{~d}$ at $28{ }^{\circ} \mathrm{C}$. The surviving bacteria were then washed off the plates and, after making 10 -fold serial dilutions, the cultures were used to inoculate peas growing in nitrogen-free mineral salts (PF) medium (Beringer, 1974).

Physical analysis of plasmids. Details of the methods for plasmid isolation are given in the accompanying paper (Hirsch et al., 1980). However, in this study electrophoresis on Tris/borate agarose gels was for $16 \mathrm{~h}$ at $100 \mathrm{~V}$ and $20 \mathrm{~mA}$.

\section{RESULTS}

Transfer of nodulation ability from strain TOM derivatives to strain 300 derivatives

Strain TOM forms abundant nitrogen-fixing nodules on Wisconsin Perfection, JI 241 and cv. Afghanistan; strain 3841 (300 Str-r) nodulates Wisconsin Perfection proficiently, but only very rarely forms nodules on JI 241 or cv. Afghanistan. When derivatives of strain 3841 were recovered from the rare nodules induced on JI 241 these clones were not enhanced in their ability to nodulate JI 241 compared to the original strain 3841 : even after three serial passages through nodules of JI 241 the derivatives of strain 3841 still showed no significant improvement in their capacity to nodulate this host. This result suggests that the occasional nodulation of JI 241 by strain 300 derivatives was not due to selection of genetically modified derivatives of $R$. leguminosarum strain 3841 .

Crosses were performed using strain 3706 (TOM Rif-r) as the donor and Str-r derivatives of strain 300 as recipients in an attempt to transfer the host specificity of TOM (i.e. nodulation ability for cv. Afghanistan and JI 241) to the recipient strain. Strain 3841 (300 Str-r) was the first recipient used. Following counterselection of the donor, 10 -fold serial dilutions of the products of the cross were used to inoculate JI 241. No nodulation of JI 241 by derivatives of strain 3841 was detected after these crosses. However, subsequent reconstruction experiments suggested that this strain was not a suitable recipient in which to select for transfer of nodulation ability because, when present in excess, it interfered with nodulation of JI 241 by TOM, and presumably $\mathrm{Nod}^{+}$derivatives of 3841 would also fail to induce nodules on JI 241 in the presence of an excess of strain 3841 itself.

As an alternative strategy, strain 16015 (300 Str-r Spc-r Nod ${ }^{-}$) was used as a recipient and selection was made for restoration of the ability to nodulate Wisconsin Perfection following crosses with TOM or TOM derivatives. This recipient strain, 16015, nodulated neither Wisconsin Perfection nor JI 241, nor two other members of the Viciaceae that were tested, namely, Lathyrus odoratus and Vicia faba (Brewin et al., 1980). Reversion to a nodulating phenotype was undetectable (frequency $<10^{-9}$ ), and the mutation is correlated with a deletion of the $205 \times 10^{6} \mathrm{~mol}$. wt plasmid of strain 300 (Fig. 1, and Hirsch et al., 1980). The mutant lacks genes for nodule function $\left(\mathrm{Fix}^{-}\right)$as well as nodule formation (Nod-) (Buchanan-Wollaston et al., 1980).

Following five separate crosses using 3706 (TOM Rif-r) or TOM as donors, nodules arose on Wisconsin Perfection when the inoculum mixture (following counter selection of the donor) contained as few as $10^{6}$ or $10^{5}$ viable bacteria. Forty clones were recovered from surface-sterilized nodules of Winconsin Perfection, each from a different nodule on a different host plant. After purification by streaking twice for single colonies all but one of these clones had the antibiotic resistance markers (Str-r Spc-r) expected for derivatives of strain 16015, and, unlike the donor strain 3706, they were sensitive to rifampicin. (The exception was a clone that was Rif-r Str-r Spc-s and appeared to be a spontaneous streptomycin-resistant derivative of the donor, strain 3706.) Five of these clones were examined further and shown to be derivatives of strain 16015 by the following additional criteria: they had the same 'fingerprint' as strain 16015 when tested for intrinsic resistance to a range of antibiotics (Josey et al., 1979); the pattern of bacteriocin production was the same as for strain 16015, with a small but no medium bacteriocin; and the physical analysis of 
plasmid DNA by agarose gel electrophoresis revealed the three plasmid bands characteristic of strain 16015.

All 39 of the derivatives of strain 16015 recovered from nodules of Wisconsin Perfection were, after re-purification, re-tested for nodulation ability. Not only did these clones nodulate Wisconsin Perfection but they also nodulated JI 241 and all five clones that were tested also nodulated cv. Afghanistan. (The clones recovered from surface-sterilized nodules after plant tests all had the expected genetic markers.) All except one of the clones tested produced pink, acetylene-reducing nodules on all three pea lines. (The exceptional clone formed green nodules that did not reduce acetylene on all three pea lines, and we do not know how this arose.) In parallel control experiments, 10 separate clones of TOM formed abundant pink, acetylene-reducing nodules on all three pea lines; 10 clones of strain 16015 nodulated none of the hosts and 10 clones of strain 3841 nodulated Wisconsin Perfection, but not JI 241 or cv. Afghanistan.

Because the specialized host-range properties of TOM were co-transferred at high frequency when nodulation ability for Wisconsin Perfection was transferred to strain 16015 , an attempt was made to separate these two genetic characters by selecting directly for the transfer of nodulation ability for JI 241. Crosses were performed using strain 3706 as donor and strain 16015 as recipient and, following counterselection of the donor, the products of the crosses were used to inoculate JI 241 after 10 -fold serial dilution of the inoculum mixture. The results were identical to those obtained when selection was made on Wisconsin Perfection in the same crosses. Nodulation was obtained when the inoculum mixture (recipients and transconjugants from the cross) contained more than $10^{5}$ to $10^{6}$ rhizobia. All 10 clones recovered from surface-sterilized nodules were shown to be derivatives of strain 16015 by all the criteria described above, and all formed abundant pink, acetylene-reducing nodules on Wisconsin Perfection as well as on JI 241 and cv. Afghanistan.

In order to estimate the frequency of transfer of nodulation ability for JI 241 to strain 16015 a reconstruction experiment was performed using a derivative of 16015 that had acquired nodulation ability from strain 3706 and was now capable of nodulating JI 241 . An inoculum mixture containing fewer than 10 colony-forming units (c.f.u.) of the nodulating derivative of strain 16015 , together with $10^{7}$ c.f.u. of strain 16015 , caused nodulation of JI 241. This indicates that the transfer of nodulation ability for JI 241 occurred at a frequency of $10^{-5}$ to $10^{-6}$ per recipient, i.e. the same frequency as was observed for the transfer of nodulation ability for Wisconsin Perfection in the same crosses. A similar reconstruction experiment involving an inoculum containing 10 c.f.u. of the nodulating 16015 derivative, together with $10^{7}$ c.f.u. of strain 3841 (300 Str-r) produced no nodules on JI 241 ; apparently a wild-type strain 300 inhibits nodulation of JI 241 by TOM and similar derivatives, and hence strain 3841 was an unsuitable recipient for crosses with TOM derivatives.

\section{Chromosome donor ability of TOM derivatives}

In the crosses described above between strains 3706 and 16015, nodulation ability for Wisconsin Perfection, nodulation ability for JI 241, and acetylene reduction activity $\left(\mathrm{Fix}^{+}\right)$on both host plants were transferred together. Because it was impossible to select directly for transfer of nodulation ability for JI 241 from strain 3706 to 3841 we could not eliminate the possibility that this character could be transferred independently and at a higher frequency than the wild-type alleles required to restore strain 16015 to a $\mathrm{Nod}^{+} \mathrm{Fix}^{+}$ phenotype on Wisconsin Perfection. However, the close correlation of these characters and the rather high transfer frequency observed $\left(10^{-5}\right.$ to $10^{-6}$ per recipient) suggested the involvement of transmissible plasmids and it was therefore necessary to establish whether these markers were, in fact, transferred at frequencies higher than those of chromosomal genes. 
Using as donor either strain 3706 or 3706 containing the P-group R-plasmid pJB3JI (a kanamycin-sensitive derivative of R68.45 obtained after treatment with $N$-methyl- $N^{\prime}$ nitro- $N$-nitrosoguanidine), transfer of prototrophic alleles to strain 6007 (300 $\mathrm{Phe}^{-} \mathrm{Trp}^{-}$ Nod- $^{-}$Str-r) was investigated. When the donor strain contained pJB3JI, $\mathrm{Phe}^{+}$and $\mathrm{Trp}^{+}$ recombinants arose at frequencies of about $10^{-6}$ per recipient, but, in the absence of an introduced sex plasmid, strain 3706 did not transfer these chromosomal genes at frequencies that could be detected above the spontaneous reversion rates for the phe and trp alleles (i.e. $<10^{-8}$ per recipient). Thus, the transfer of nodulation ability and host-range characteristics from TOM derivatives was at least two orders of magnitude higher than the transfer of chromosomal markers.

\section{Bacteriocin production}

In all other cases where transfer of nodulation ability to strain 16015 has been observed (Brewin et al., 1980) this has been associated (either stably or unstably) with the transfer of a plasmid coding for a medium bacteriocin $\left(\mathrm{Med}^{+}\right)$which is transferred at high frequencies $\left(10^{-2}\right.$ per recipient) between strains. We therefore investigated the production of bacteriocins by TOM and derivatives of strain 16015 which had received nodulation ability from TOM. When grown on rich (TY) plates, strain TOM (and 3706) produced a cleared zone of 30 to $40 \mathrm{~mm}$ diameter in an overlay of strain 248 (an indicator of small bacteriocins), and when grown on minimal $Y$ plates a cleared zone of $8 \mathrm{~mm}$ was detected using strains 239, 300 or, more indistinctly, 336 as indicators for medium bacteriocin. Strain 16015 produced only small bacteriocins (Hirsch, 1979). Ten derivatives of 16015 that had acquired nodulation ability and host-range characteristics from TOM or 3706 also produced the small bacteriocin (characteristic of strain 300), but none of them produced a medium bacteriocin either on rich or minimal plates. Moreover, following a cross between strains TOM and 16015, all 700 recipient clones tested on rich and minimal plates using strain 239 as the indicator strain failed to produce medium bacteriocin. Thus, unlike the transfer of nodulation ability from strains containing pRL1JI, pRL3JI and pRL4JI (Brewin et al., 1980) the transfer of nodulation ability and host-range specificity from TOM is apparently not associated with the transfer of a plasmid coding for medium bacteriocin production.

\section{Plasmid isolation from nodulating transconjugants}

The plasmid DNA of strains TOM, 16015 and six of the Nod $^{+}$transconjugant clones was investigated by electrophoresis on agarose gels (Fig. 1). Lysates from strain TOM, and its derivative 3706, contained three plasmid bands (Fig. 1, track 4); by comparison with the mobility of pJB5JI and the resident plasmids of strain 300 (Casse et al., 1979; Hirsch et al., 1980), the molecular weights of the plasmids from strain TOM were approximately $140 \times 10^{6}, 160 \times 10^{6}$ and $220 \times 10^{6}$. In all the $\mathrm{Nod}^{+}$transconjugants (including the one that was $\mathrm{Fix}^{-}$) there was a single extra band compared to strain 16015 (Fig. 1, track 3). Regardless of which host plant (Wisconsin Perfection or JI 241) was originally used to select the $\mathrm{Nod}^{+}$transconjugants, the new plasmid band was always the same size (about $160 \times 10^{6}$ ) as the middle-sized band of strain TOM. This band is presumably the plasmid, which we term pRL5JI, identified genetically as carrying genes for nodulation $\left(\mathrm{Nod}^{+}\right)$, nodule function $\left(\mathrm{Fix}^{+}\right)$and host-range specificity.

\section{Absence of plasmid incompatibility}

The introduction of pRL5JI from strain TOM never resulted in the elimination of any of the resident plasmids from strain 16015. Furthermore, when an additional nodulation plasmid, pJB5JI (a kanamycin-resistant derivative of pRL1JI), was introduced from $R$. leguminosarum strain T3 (Fig. 1, track 6) into a derivative of 16015 containing pRL5JI, 


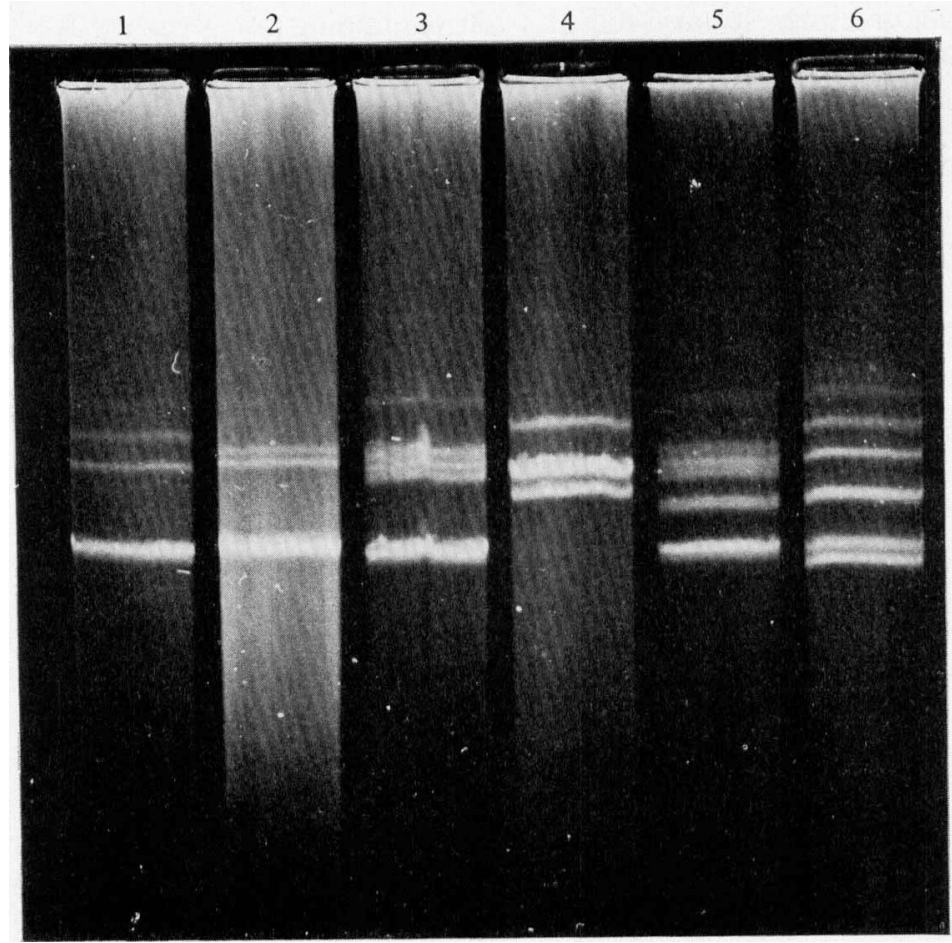

Fig. 1. Separation of large plasmids from strains of $R$. leguminosarum by agarose gel electrophoresis. Track 1, strain 3841; 2, 16015; 3, 16015(pRL5JI); 4, TOM; 5, 16015(pRL5JI)(pJB5J1); 6, T3. In strain T3 the third-smallest band corresponds to pJB5JI. Note that in strain 3841 and some of the other lysates from 300 derivatives two additional very large plasmid bands are visible, in addition to the three plasmid bands previously described for this strain. Note also that the smallest band visible in strain 3841 is represented as a doublet in the 300 derivative containing pJB5JI (strain T3): see Hirsch et al. (1980) for a discussion of these features.

there was no elimination of pRL5JI or any of the other plasmids of strain 16015 (Fig. 1, track 5). Thus, incompatibility must be very low or non-existent between pRL5JI, pRL1JI and the corresponding resident (partially deleted) nodulation plasmid of strain 16015 .

There was also no evidence of functional interference between the two nodulation plasmids pRL5JI and pJB5JI. Derivatives of TOM containing the additional plasmid pJB5JI and derivatives of 16015 which contained pRL5JI and, in addition, pJB5JI were still able to form Fix ${ }^{+}$nodules on JI 241 as well as on Wisconsin Perfection, whereas derivatives of 16015 containing pJB5JI alone were unable to nodulate JI 241 although they had acquired the ability to nodulate Wisconsin Perfection.

As further evidence of the distinctness of pJB5JI and pRL5JI, TOM derivatives containing pJB5JI were crossed with the $\mathrm{Nod}^{-}$strain 16015. Selection was made for transfer of kanamycin resistance (on pJB5JI) to 16015 , which occurred at a frequency of $10^{-2}$ per recipient. Ten purified transconjugants were tested for nodulation ability; they nodulated Wisconsin Perfection (as is expected for any derivative of 16015 containing pRLIJI or its derivative pJB5JI) but none nodulated JI 241. These results confirm the compatibility of pRL1JI (pJB5JI) and pRL5JI since the introduction of pJB5JI did not eliminate the resident nodulation ability of strain TOM. They also show that pJB5JI could be transferred from TOM to strain 300 derivatives at rates comparable to those observed between different derivatives of strain 300 but that there was no high frequency co-transfer of the nodulation characteristics of TOM (i.e. pRL5JI) with pJB5JI.

Similar experiments were performed following the introduction of two other trans- 
missible plasmids, pVW3JI and pVW5JI (kanamycin-resistant derivatives of pRL3JI and pRL4JI, respectively; Brewin et al., 1980), into strain 3706. (Unlike pRL1JI, these plasmids do not normally confer nodulation ability to strain 16015.) Just as was observed for pJB5JI, these plasmids did not eliminate the special nodulation characteristics of TOM from the recipient strain; nor in subsequent crosses to strain 16015 (selecting for transfer of kanamycin resistance) was there high frequency co-transfer of nodulation ability either on Wisconsin Perfection or on JI 241. (Ten re-purified transconjugant clones were examined in each case.) These results are in contrast to those in which the introduction of pVW3JI or pVW5JI into strains containing the nodulation plasmid pRL1JI apparently resulted in recombination between the resident plasmid and the introduced plasmid, such that subsequent transfers of kanamycin resistance were always associated with co-transfer of nodulation ability to strain 16015 (Brewin et al., 1980).

The only kind of functional interaction observed between pJB5JI, pVW3JI or pVW5JI and host-coded functions of strain TOM involved bacteriocin production. Derivatives of strain TOM containing these plasmids produced no small bacteriocin(s) and the diameter of the cleared zone obtained using strain 239 as an indicator (for medium bacteriocin) was reduced from 9 to $5 \mathrm{~mm}$. (Although the natural bacteriocinogenic plasmids, pRLIJI, pRL3JI and pRL4JI all produce a medium bacteriocin as well as repressing small bacteriocin, the derived plasmids used here have the transposon Tn5 inserted into the region specifying medium bacteriocin production.) The most probable interpretation of these results is that strain TOM produces several bacteriocins, some of which (the small and at least one medium bacteriocin) are repressed by these plasmids.

\section{DISCUSSION}

We report here the identification of a plasmid, pRL5JI, of molecular weight about $160 \times 10^{6}$ which originated in $R$. leguminosarum strain TOM and is transferred to derivatives of strain 300 at a frequency of $10^{-5}$ to $10^{-6}$ per recipient. Like the previously reported plasmid pRL1JI (Johnston et al., 1978; Hirsch, 1979; Brewin et al., 1980; BuchananWollaston et al., 1980), pRL5JI appears to carry genes for nodulation ( $\mathrm{Nod}^{+}$) and fixation $\left(\mathrm{Fix}^{+}\right)$which restore a wild-type phenotype to strain 16015, a plasmid deletion mutant. The special property of pRL5JI is that it specifies the particular host-range characteristics of strain TOM (from which it was derived), namely the ability to nodulate cv. Afghanistan and $J \mathbf{~} 241$, in addition to a 'normal' pea variety, Wisconsin Perfection.

We cannot rigorously exclude the possibility that nodulation ability for JI 241 and cv. Afghanistan might be transferred to strain 300 derivatives separately and at much higher frequency than the genes necessary to restore to strain 16015 its ability to nodulate Wisconsin Perfection. However, this possibility is unlikely because only one new plasmid band was observed in derivatives of 16015 that had acquired the ability to nodulate Wisconsin Perfection and $\mathrm{JI} 241$, and this band corresponded in size to one of the three plasmid bands seen in strain TOM.

The transfer of nodulation ability from TOM (by pRL5JI) differed from that associated with other transmissible plasmids from $R$. leguminosarum, namely pRL1JI, pRL3JI and pRL4JI. These three plasmids all specify production of similar medium bacteriocins and repress the production of small bacteriocins; the plasmids are highly transmissible $\left(10^{-2}\right.$ per recipient) and mobilize chromosomal genes at detectable frequencies $\left(10^{-6}\right.$ to $10^{-7}$ per recipient); and these plasmids cannot co-exist within the same cell without apparently undergoing recombination (i.e. they are in the same incompatibility group) (Brewin et al., 1980). In all these respects pRL5JI is different. Not only is the transfer frequency much lower, but there is no associated transfer of medium bacteriocin production. Moreover, pRL5JI was found to be compatible with the other three plasmids and not to show 
functional interference with them. No recombination was observed between PRL5JI and derivatives of the other three plasmids, but in the absence of incompatibility, there would have been no selection for the products of recombination; therefore its occurrence is not excluded.

The existence of derivatives of strain 300 possessing or lacking the ability to nodulate JI 241 and cv. Afghanistan should now facilitate the biochemical analysis of this hostRhizobium incompatibility.

We acknowledge technical assistance from Miss E. Wood, and thank Professor D. A. Hopwood for his careful scrutiny of the manuscript.

\section{REFERENCES}

BERINGER, J. E. (1974). R factor transfer in Rhizobium leguminosarum. Journal of General Microbiology 84, 188-198.

Beringer, J. E., Hoggan, S. A. \& Johnston, A. W. B. (1978). Linkage mapping in Rhizobium leguminosarum by means of $\mathbf{R}$ plasmid-mediated recombination. Journal of General Microbiology 104, 201-207.

Brewin, N. J., Beringer, J. E., Buchanan-WolLASTON, A. V., Johnston, A. W. B. \& Hirsch, P. R. (1980). Transfer of symbiotic genes with bacteriocinogenic plasmids in Rhizobium leguminosarum. Journal of General Microbiology 116 , 261-270.

Buchanan-Wollaston, A. V., Beringer, J. E., Brewin, N. J., Hirsch, P. R. \& Johnston, A. W. B. (1980). Isolation of symbiotically defective mutants of Rhizobium leguminosarum by insertion of the transposon Tn5 into a transmissible plasmid. Molecular and General Genetics 178, 185-190.

Casse, F., Boucher, C., Julliot, J. S., Michel, M. \& DÉNARIÉ, J. (1979). Identification and characterization of large plasmids in Rhizobium meliloti using agarose gel electrophoresis. Journal of General Microbiology 113, 229-242.

Gross, D. C., Vidaver, A. K. \& Klucas, R. V. (1979). Plasmids, biological properties and efficacy of nitrogen fixation in Rhizobium japonicum strains indigenous to alkaline soils. Journal of General Microbiology 114, 257-266.

HaAs, D. \& Holloway, B. W. (1976). R factor variants with enhanced sex factor activity in Pseudomonas aeruginosa. Molecular and General Genetics 144, 243-251.

HiRsCH, P. R. (1979). Plasmid-determined bacteriocin production by Rhizobium leguminosarum. Journal of General Microbiology 113, 219-228.

Hirsch, P. R., van Montagu, M., Johnston, A. W. B., BrewiN, N. J. \& Schell, J. (1980). Physical identification of bacteriocinogenic, nodulation and other plasmids in strains of Rhizobium leguminosarum. Journal of General Microbiology 120, 403-412.

Holl, F. B. (1975). Host plant control of the inheritance of dinitrogen fixation in the PisumRhizobium symbiosis. Euphytica 24, 767-770.

JoHnston, A. W. B. \& BERINGER, J. E. (1975). Identification of the Rhizobium strains in pea root nodules using genetic markers. Journal of General Microbiology 87, 343-350.
Johnston, A. W. B. \& Beringer, J. E. (1976). Pea root nodules containing more than one Rhizobium species. Nature, London 263, 502-504.

Johnston, A. W. B., Beynon, J. L., BuchanaNWollaston, A. V., Setchell, S. M., Hirsch, P. R. \& Beringer, J. E. (1978). High frequency transfer of nodulating ability between strains and species of Rhizobium. Nature, London 276, 635-636.

Josey, D. P., Beynon, J. L., Johnston, A. W. B. \& BERINGER, J. E. (1979). Strain identification in Rhizobium using intrinsic antibiotic resistance. Journal of Applied Bacteriology 46, 343-350.

Lie, T. A., Hille, D., Lambers, R. \& Houwers, A. (1976). Symbiotic specialisation in pea plants: some environmental effects on nodulation and nitrogen fixation. In Symbiotic Nitrogen Fixation in Plants, pp. 319-333. Edited by P. S. Nutman. Cambridge: Cambridge University Press.

LoPER, J. E. \& KaDo, C. E. (1979). Host range conferred by the virulence-specifying plasmid of Agrobacterium tumefaciens. Journal of Bacterio$\log y$ 139, 591-596.

van Montagu, M. \& Schell, J. (1979). The plasmids of Agrobacterium tumefaciens. In Plasmids of Medical, Environmental and Commercial Importance, pp. 71-95. Edited by K. N. Timmis \& A. Pühler. Amsterdam: Elsevier/ North Holland.

Moore, L., Warren, G. \& Strobel, G. (1979). Involvement of a plasmid in the hairy root disease of plants caused by Agrobacterium rhizogenes. Plasmid 2, 617-626.

Nuti, M. P., Lepidi, A. A., Prakash, R. K., Schilperoort, R. A. \& CANNoN, F. C. (1979). Evidence for nitrogen fixation (nif) genes on indigenous Rhizobium plasmids. Nature, London 282, 533-535.

Thomashow, M. F., Panagopoulos, C. G., GorDON, M. P. \& Nester, E. W. (1980). Host range of Agrobacterilim tumefaciens is determined by the Ti plasmid. Nature, London 283, 794-796.

Vincent, J. M. (1970). A Manual for the Practical Study of the Root Nodule Bacteria. Oxford: Blackwell Scientific Publications.

WinarNo, R. \& LIE, T. A. (1979). Competition between Rhizobium strains in nodule formation: interactions between nodulating and non-nodulating strains. Plant and Soil 51, 135-142. 